AWEJ for Translation \& Literary Studies, Volume 4, Number2. May 2020 DOI: http://dx.doi.org/10.24093/awejtls/vol4no2.13

Pp. 167-176

\title{
White Identity Problems in Kurt Vonnegut's Science Fiction
}

\section{Meryem MENGOUCHI}

LLC Lab

Department of English, Faculty of Letters and Languages

University of Aboubekr Belkaid, Tlemcen - Algeria

\section{Wassila HAMZA REGUIG MOURO}

LLC Lab

Department of English, Faculty of Letters and Languages

University of Aboubekr Belkaid, Tlemcen, Algeria

\begin{abstract}
:
Kurt Vonnegut as a American post-war author sought to voice his anger with American foreign policy, arguing that it had a pervasive impact on the white middle-class individual. He used two mains types of protagonists to represent the struggle of this white middle-class individual. The first is a post-nuclear hero that is careless and indifferent to things around them. The second is characterized by a sort of obsessive madness about people's well being and love. Both are victims of the atomic annihilation age which occurred after the Second World War and the fears that emanated of it. They have to look at their universe crawling to destruction and teach themselves to cope with it. The only escape that is possible for these protagonists is death. Vonnegut thus makes self-deluded, anxious, and mad protagonists to show a white middle-class individual who suffers an identity crisis because the discourses and claims of the government alienate them. This special middle-class is a minority that is marginalized by the mainstream bourgeois culture. Loneliness is a keyword in his works, he often depicts Americans around the world as lonely because the foreign policy of their country makes them misunderstood among others, and does not represent their true feelings. Lonesome No More and God Bless You Mr. Rosewater are novels that show kindness towards simple Americans. Understanding the importance of this white American minority will help understanding contemporary American politics and particularly the kind of people that are elected in America.
\end{abstract}

Keywords: alienation, american identity, atomic annihilation, cat's cradle, god bless you, $\mathrm{mr}$. rosewater, kurt vonnegut, post-nuclear hero, postmodern prometheus, , post-war period, science fiction, science fiction protagonist, self-delusion, slapstick, slaughterhouse-five, white middleclass American

Cite as: MENGOUCHI, M., \& HAMZA REGUIG MOURO, W. (2020). White Identity Problems in Kurt Vonnegut's Science Fiction. Arab World English Journal for Translation \& Literary Studies 4 (2) 167-176 . DOI: http://dx.doi.org/10.24093/awejtls/vol4no2.13 
AWEJ for Translation \& Literary Studies Volume, 4 Number 2 May 2020

White Identity Problems in Kurt Vonnegut's Science

Mengouchi \& Hamza Reguig Mouro

\section{Introduction}

Through an analysis of Vonnegut's major works, particularly Cat's Cradle, Slaughterhouse-Five, Slapstick, and Galàpagos, one realizes that Vonnegut did not write Science Fiction (SF) for the sake of fantasizing about the future only. His approach to the universe around him, and the future of the earth, was somewhat pessimistic, he even predicted a disastrous - and accelerated - end of the world. Kurt Vonnegut's use of Science Fiction is undoubtedly rebellious. He writes merely to express anger, disapproval, and to show his resistance to the imposed systems. He stands against everything that turns out to be abusive to the future of man, like political systems or cultural agents that justify harmful practices like racism and war.

Vonnegut is an anti-conformist author who hated (then left) his job at General Electric because it obliged him to tell lies (Allen \& Vonnegut, 2003). His non-conformist ideas occur in his works in a very subtle way. Some of his protagonists are "post-nuclear heroes," who are loners, and for whom science is an indifferent force that "assaults them every moment of their lives" (Boon, 2006, p.19). These heroes live in a "post-nuclear age" (a term used by the American critic Donald E. Morse), which comes in SF as the age of destruction. Though different authors attempted to represent the positive side of science, most of the population was already convinced that the end of the world was near, and that they were living in an age of "atomic annihilation" (Morse, 2006, p.84-85). In this period, atomic destruction became "the number one public fear" (83), which yielded into the "post-nuclear hero" as a recurrent figure in the literature of the period.

The people represented by, and in, Vonnegut's works of SF are helpless white Americans; who rejected the living conditions in their country during the post-war era and prepared themselves for the end of humanity. Morse cites authors who also made writing about doom the core element of SF, like Ray Bradbury, who wrote about humans colonizing Mars as a consequence of the destruction of the earth in The Martian Chronicles (as cited in Morse 2006, p.85). American SF author Philip K. Dick is also mentioned by Morse to argue that any "responsible" writer would have become an "involuntary [crier] of doom, because doom is in the wind" (p. 85). Likewise, Vonnegut often mentioned that his works meant to raise people's awareness about their world, their politicians, and about the danger of science (Allen \& Vonnegut, 2003). He often spoke of the function of the author, saying that writers are the "canaries in the coal mine" or the alarm bells, who have to warn about danger before it happens (Vonnegut, 2006, p. 94).

What is typical about the cited writers is that they lived within the same period; they witnessed the end of the war and its consequences (the atomic age). They have been terrified by the development of events, and all of them used SF to speak about their disapproval and rejection of such policies, especially when the US government started war in Vietnam. The people who consumed such literature were people who could see what was going wrong with the world around them and who felt terrible about it. Likewise, Vonnegut's characters often feel depressed, abandoned, anxious, or even marginalized by the mainstream around them, which denotes the

Arab World English Journal for Translation \& Literary Studies 
AWEJ for Translation \& Literary Studies Volume, 4 Number 2 May 2020

White Identity Problems in Kurt Vonnegut's Science

Mengouchi \& Hamza Reguig Mouro

existence of a white minority within the majority, usually unheard or ignored by the mainstream culture, who justifies war.

\section{The "Post-Nuclear Hero" and Character}

The SF writer occupies a position that elevates the genre to high art by acting as a prophet writer. Such is the case of Kilgore Trout, the fictional SF author in Vonnegut's works, who prophesies doom, thus embodying the redemption of the SF writer as a prophet of the atomic age (Morse, 2006). The SF work inspires from the period of its writing even if the setting is in the future. The 1950s in America for example was a period in which Americans were engrossed by the idea of atomic annihilation. They were shocked by the use of the bomb against civilians after the Hiroshima and Nagasaki events (Morse, 2006), which they reflected in the literature of the period (and imagined consequences set in the future).

These "New Wave Science Fiction Writers" concerned themselves with the sociological impact of their works as expressions of satire, characterized merely by their sarcasm and pessimism, and depicting the future as "dark and miserable" (Mann, 2001, p. 18). The writers of the period become prophets of doom, and the things-go-wrong attitude ${ }^{\mathrm{i}}$ becomes the common way of writing SF. The protagonist is thus someone who has to face the trouble of living in destruction and coping with it. They are someone who tries to cope with the chaos around them (like Jonah in Cat's Cradle), someone trying to give sense to the world (Eliot in God Bless You, Mr. Rosewater), or a loner who goes senseless and careless about the world (like Dr. Hoenikker in Cat's Cradle).

Kevin A. Boon speaks of the "Post-nuclear heroes" whom he describes as loners that are affected neither by science nor by religion (Boon, 2006, p.20). They are characters who have to surrender to death because it is the only escape they find around them. He concludes:

The post-nuclear hero achieves heroic proportions by asserting his/her individual will in the midst of chaos. Order does not have to be regained. The enemy does not have to be vanquished. All sources of conflict do not have to be resolved. Closure is not mandatory (Boon, 2006, p.20)

Science in such novels is one of the different forces that oppress them. Though Boon chose Felix Hoenikker as the loner in Cat's Cradle, other characters are also loners in the same novel (maybe even more than Felix). Jonah and Newt, for example, feel assaulted by the consequences of Dr. Hoenikker's inventions (the atomic bomb and Ice-nine that caused the end of the world). One more loner is Billy Pilgrim in Slaughterhouse-Five. He is a young man who was driven to fight in a war against his will. Billy did not want to be in war and was constantly trying to die to put an end to his struggle.

In the case of Billy Pilgrim, death is presented as the only escape from a fate he never wanted. He is the center in his environment, yet, he is not represented as a brave warrior. The main 
AWEJ for Translation \& Literary Studies Volume, 4 Number 2 May 2020

White Identity Problems in Kurt Vonnegut's Science

Mengouchi \& Hamza Reguig Mouro

thing about him is that he is rather realistic at war; he did not embody any of the myths of heroic fighters. He was a simple young man who was not ready to fight.

For Billy, it was unfortunate to have to survive each time he tried to let himself die. He was traveling back and forth in time because the aliens from the fictional planet Tralfamadore captured him. Though the time-traveling in the narrative breaks all the rules of traditional storytelling, for Billy, it meant being stuck in life and being unable to make one's fate better. Boon (2006) explains that "in post-nuclear science fiction, death is presented as the conclusion of a game we create for ourselves to play" (p.20). Thus, Billy, being able to foresee the future, is overwhelmed by the game around him. The game is a reference to government decisions like going to war, the Dresden firebombing, etc. All that makes him feel like death is the only possible conclusion for the meaninglessness of life.

Mary O'hare in Slaughterhouse-Five is also a post-nuclear hero who feels alien to her culture. Mary does not consider death as the only option though she does show some sort of melancholy about the world. She considers the young men who went to war as children who were sent to death. Mary showed a lot of anger with the writer of the book in the novel because she thought he was going to write another "war glorifying novel," which is why Vonnegut decides to call it the Children's Crusade (Vonnegut, 2007, p. 16).

Cat's Cradle published in 1963 featured the same idea as that of Mary in SlaughterhouseFive. In this novel, Ambassador Minton stated that the war was actually fought by children (Vonnegut, 2011, p.181). In his speech during the celebration entitled "In Memory of War Martyrs," he spoke about the young men who fought the war and called them children. In fact, Cat's Cradle expressed Vonnegut's view about war in the voice of ambassador Minton saying:

When we remember wars, we should take off our clothes and paint ourselves blue and go on all four all day long and grunt like pigs, that would surely be more appropriate than noble oratory and shows of flags and well oiled guns (Vonnegut, 2011, p.182).

There is a common feeling of anxiety shared between these characters, as a result of the events of their age. They deliver a truthful account of the feeling of the common individual in the twentieth century. This leads to the questioning of the true feelings of these groups as opposed to their societies, in which they often feel alienated. Vonnegut's protagonists are usually white middleclass Americans from the Midwest, often from his hometown, Indianapolis. They all share a common distrust of their culture and think that all life is meaningless.

\section{Vonnegut's White Minority}

Vonnegut keeps going back to his disillusioned white protagonists in many novels (Cat's Cradle, Slaughterhouse-Five, Slapstick, GBY). He also depicts them as feeling lonely in America. In Cat's Cradle, he argues in the voice of Mrs. Minton that Americans are hated everywhere they 
AWEJ for Translation \& Literary Studies Volume, 4 Number 2 May 2020

White Identity Problems in Kurt Vonnegut's Science

Mengouchi \& Hamza Reguig Mouro

go because of the country's foreign policy and that they are in constant search for love (Vonnegut, 2011, p.70).

Vonnegut adds the description Lonesome no More to the title of the novel Slapstick, in which he assigns codes arbitrarily to different people in the country. In case of a sudden war or atomic catastrophe, the people who are assigned these codes can find each other and live together as a family. In Slaughterhouse-Five, he describes the American soldiers as the most desperate, the poorest, and the dirtiest of all the other soldiers, saying:

Many novelties have come from America. The most startling of these [...] a mass of undignified poor. They do not love one another because they do not love themselves. Once this is understood the disagreeable behavior of American enlisted men in German prisons ceases to be a mystery (Vonnegut, 2007, p.85).

He explains that even their outfits were not well fashioned as those of the soldiers from other countries. The enlisted American men had sterilized old suits "obviously made for [other men] ," gifted from a "nose-holding charity" (Vonnegut, 2007, p.86).

Vonnegut goes on to describe the American enlisted soldiers' behaviors to each other and towards other soldiers at war. He says that they constantly lacked fraternity and politeness to each other because they were taught to hate themselves for their poverty.

They were known everywhere to be the most self-pitying, least fraternal and dirtiest of all prisoners of war ... They despised any leader from among their own number, refused to follow or even listen to him, on the grounds that he was no better than they were, that he should stop putting on airs. (Vonnegut, 2007, p. 87)

Vonnegut explains this self-pitying attitude of the American soldiers as a lack of love and consideration from the American government towards its people. He says America is the wealthiest country, and the most common belief among Americans is that they can easily become rich, yet, they remain poor and disrespected (Vonnegut, 2007,pp.85-86).

Finally, in $G B Y$, Eliot, the protagonist, tries to give love to all people. Jerome Klinkowitz, the American scholar and critic, analyzes Vonnegut's different references to the feeling of loneliness and argues that it is due to the changing American Dream. America, according to Klinkowitz, needs a new American Dream, because the American Dream people believed in during the early twentieth century did not include living equally with the Blacks. Besides, the Economic Crisis of 1929 was a direct contributor in creating this feeling of depression and loneliness because Americans were used to a better (or higher) living standard (Klinkowitz, 1982, p. 62)

Arab World English Journal for Translation \& Literary Studies 
Vonnegut's plots show characters who only feel psychologically relieved in the odd and bizarre turns of events of the SF setting. Some of them identify with SF texts and authors they read (like Eliot Rosewater with Kilgore Trout) because they usually feel marginalized by their cultures and politics. The things that make these characters feel psychological relief are inspired from the real as the author, Vonnegut, himself often makes references to real events from the history and politics of America. This fact is not a simple act of fiction but part of the self-referentiality of the text.

The assumption that the white middle-class male characters feel represented in the SF work comes in Vonnegut's works in two different forms. First, when the characters feel lonely, desperate, they try to help others but find themselves helpless in front of the general status quo in their lives. Their sadness for humanity makes them into other versions of Prometheus. If Frankenstein was Mary Shelley's Modern Prometheus, then these characters are Vonnegut's different forms of a Postmodern Prometheus. Like him, they live in continuous pain and agony. They see things going wrong around them, become anxious, nihilist in some cases, sometimes they try to fix things but are defeated.

The Promethean protagonists live in total sadness until the end and undergo the subversive consequences, just like the people they try to help. Vonnegut's characters find relief and peace in the chaos of things around them, not because the chaos is their favorite aspect, but because there is the disruption of the imposed systems in chaos. Just like Prometheus, they are rebellious, and they want to break the conformist systems that control Man. These characters are Mr. Rosewater in GBY, the twins in Slapstick, Or Lonesome No More, Jonah in Cat's Cradle, and somehow, natural selection (metaphorically) in Galäpagos (1985).

Eliot Rosewater, for example, had a strong love and will to help others. He gave up his father's wealth because he refused to live by the fake standards of a society of appearances. He chose to be a wanderer in America, shared everything he owned in an office devoted to the people in need of help, and held long conversations with them. The novel does not include SF, but glorifies SF authors. Eliot, the protagonist, crushes into a SF authors convention and says he loved them because they were the only ones "crazy" enough to be aware that there was a "terrific" change in the world. For Rosewater, SF authors are the only ones with "guts" enough to care about the future (Vonnegut, 1965, p.18). So, taking Rosewater as an example of a white-middle class male individual, it is realized that this character feels subverted by the imposed systems; he even rejected wealth and bourgeoisie for their artificiality, for a more casual lifestyle.

Eliot is the optimist philanthropist who devotes his life and money to help people around him in $G B Y$. He is Vonnegut's depiction of the sympathetic character. The novel is about the importance of kindness towards the poor and the needy, be it mundane or psychological need. The novel itself begins with a piece of advice for babies saying that during their stay on earth, the only thing they needed to do is being kind. 
The Karassii of poor people, which is set forward by Vonnegut, shares the same feelings of love and care for others. In his conversations with Rodney Allen, Vonnegut admitted having experimented with poverty in $G B Y$ by giving money to a character inspired from a real person who was actually poor (as cited in Freese 2009, p. 235). The result of his experiment was a character who gave everything he owned for the sake of spreading happiness. The Karass also occurs indirectly in Slapstick as the point in the novel is the extent of love and empathy that an individual might be able to find in cases of loneliness.

The Prometheus figure is less explicit in the novel Slapstick as the idea of the novel is to create relatives for people all around America. In the novel, inhabitants of the country are given codes that secure extended families for them in different places. The basic plot is about a philanthropist action taken by the government to make everyone happy (or at least, lonesome no more), which reflects more or less Vonnegut's obsession with happiness and well-being (Vonnegut, 1976).

The Lonesome no More in the title is a radical plan to overcome loneliness and sadness in America by assigning artificial families for each individual. Vonnegut seems to be mostly concerned with the lack of real love and good intention in America, which is why he created the Karass as opposed to the Granfalloon, both terms coined for the first time in Cat's Cradle (first published in 1963). The Karass is a family in which people share true feelings about their society and humanity. The Granfalloon denotes people who identify with each other based on subversive ideological or cultural premises, usually, something that survives upon prejudice and artificiality (what is left after removing the skin of a toy balloon) (Vonnegut, 2011, p.65). Each of Vonnegut's novels has a Karass composed of people who feel marginalized by Granfalloons (an example of a Granfalloon he mentions in Cat's Cradle is the USA) and so is the social group represented in his works, a minority (Karass) who feels under-represented in an America of Granfallonery, the karass is thus a white minority.

Other characters are not Promethean, they do not suffer for the well-being of humanity, they are rather consequences of things going wrong in society, like Billy Pilgrim in Slaughterhouse-Five, and Dwayne Hoover in Breakfast of Champions (The loners).

\section{An American Identity Crisis}

Vonnegut's characters suffer identity dilemmas. They are troubled by the loss of the morals and principles they always respected. This mode leads them to self-delusion, which, according to the American critic James Lundquist, becomes a theme in Vonnegut's satire. Indeed, the secret, which makes Vonnegut's comedy special, is its absurdity. The more absurd the situation becomes, the funnier it is (Lundquist, 1980). Klinkowitz (1982) concludes that Americans are programmed to think that they are doomed to search for things that do not exist, which is due to a loss of trust in American values and culture. Klinkowitz idea is that the values Americans were raised to respect, were not considered by their government at war.

Arab World English Journal for Translation \& Literary Studies 
What defines Vonnegut's characters is their continuous search for meaning for their lives (Klinkowitz, 1982). Vonnegut in the voice of Claire Minton explains that Americans feel lonesome and alienated everywhere they go in the world; that they search for love in forms and places where it does not exist, and that it is a problem related to the vanished frontier (Vonnegut, 2011).

Lundquist says it is "an identity fable" that is "run through Vonnegut's fictions" (Lundquist, 1980, p.25). Americans are troubled and deceived by the image of the America of the Post World War. America is the country that raises children proud of their country's peaceful constitution and its small number of soldiers, especially compared to European countries. Yet, many of its citizens are anxious because of its foreign policy during and after the Second World War. They feel alienated when their beliefs no longer conform to their present, which is affected by war and its consequences.

Claire Minton's point (that American people's alienation is a product of the vanished frontier) is further discussed by Fumika Nagano and Jerome Klinkowitz. Fumika Nagano argues that the people who believed in American democracy considered America a white society. The vanishing frontier constituted a threat to white America because it meant ethnic mingling and the end of white America (Nagano, 2009).

Vonnegut felt loneliness and longing for the community among Americans as they shifted between houses and towns, a lifestyle that was imposed on them by their economic system. Kathryn Hume argued that his melancholy is the outcome of Americans' feelings of loneliness (Hume, 1998). Most of Vonnegut's critics, mainly Jerome Klinkowitz, James Lundquist, and Kathryn Hume, have agreed on the fact that Americans feel a loneliness caused by deceit and their government's faithlessness. This condition created a constant search for a community within Americans (Hume 1998; Lundquist 1980; Klinkowitz 1982). Each of his novels provides alternatives and ways for society to recreate family bonds. Perhaps his most popular concept is that of the Extended Family, which he suggested in Slapstick. Through the Extended Family, Vonnegut allows his characters to have relatives in every American state, thus making them feel less lonesome. The idea consists of attributing code numbers to each individual, thus, each one could find a relative who had the same code number as theirs other states around the country.

Vonnegut's expression of anger against his culture and politics includes not only disillusioned characters but also irrationality and humour. He uses absurd representations like extreme transformations in human beings (from Men to half-fish in Galàpagos), grotesque human figures like Dr. Felix Hoenikker on the day the bomb was dropped on Japan, and silly illustrations of Billy Pilgrim in Slaughterhouse-Five.

\section{Conclusion}

The twentieth-century literature needed to depict different themes that represented the period, especially the post-war era. This literature about wars included feelings of disillusionment 
and distrust by individuals towards their cultures. Americans felt the risk of living in chaos after the end of the war and felt that their age was the age of atomic annihilation; they expected the catastrophe at any moment. Authors attempted to depict these fears in SF works because the danger came from science. Science had become the most dangerous thing in life since it was perceived as more harmful to human beings, than useful.

SF writers redefined the function and elements of this genre, which went from creative prophesies about the future of science to destructive expectations of the future of humanity, such themes are best represented through dystopia. Whether these writers decide willingly or unwillingly to use such a style in their literature, this genre finds itself immersed within the postwar SF novel from the very moment the themes of doom make an occurrence.

The post-nuclear literature features a post-nuclear hero who feels lonely and desperate because of their culture and politics, expecting death as the only solution out of it. Through the works of Kurt Vonnegut, this protagonist reveals himself to feel lonesome in a society that is entirely influenced by the ideals of Modernity, which legitimizes war, and submits to the discourses of their governments. Vonnegut's SF revealed the existence of a white minority within the general white majority in the United States. This group is minor because of its feelings of marginalization and disillusionment as opposed to their mainstream culture.

\title{
Notes \\ ${ }^{\mathrm{i}}$ American historian Bernard DeVoto stated that the post-War SF was all about destruction and devastation. The "Things go wrong" is the ultimate story pattern of the period with "conclusive tragedy" (cited in Bleiler and Bleiler 1998). \\ ii Term coined by K. Vonnegut in $C C$ to refer to people who share good intentions about humanity and feel they belong to the same group
}

\begin{abstract}
About the authors:
Meryem MENGOUCHI is a teacher of literary studies in the department of English, University of Aboubekr Belkaid Tlemcen. She has an M.A in Applied Literary Studies from ISLT, University of Carthage, Tunisia, and is writing a Phd thesis on the aspects of minority literature in the works of American author Kurt Vonnegut. ORCid ID: https://orcid.org/0000-0002-4138-0690
\end{abstract}

Wassila Hamza Reguig Mouro is an Associate Professor at the Department of English, University of Aboubekr Belkaid Tlemcen. She holds a Doctorate in Literature and Civilization as well as a Habilitation. Her research interests are mostly literary and turn around Postmodernism (metafiction, intertextuality, dialogism and narration...), Women's writing, Postcolonial literature and the Victorian era. ORCid ID: https://orcid.org/0000-0002-5011-3551

Arab World English Journal for Translation \& Literary Studies 
AWEJ for Translation \& Literary Studies Volume, 4 Number 2 May 2020

White Identity Problems in Kurt Vonnegut's Science

Mengouchi \& Hamza Reguig Mouro

\section{References}

Allen W. R, \& Vonnegut, K. (2003). Conversations with Kurt Vonnegut. Jackson. Miss.: Univ. Press Of Mississippi.

Bleiler, E. F., \& Bleiler, R. (1998). Science-fiction : the Gernsback years : a complete coverage of the genre magazines Amazing, Astounding, Wonder, and others from 1926 through 1936. Kent, Ohio ; London: Kent State University Press.

Boon, K. A. (2006). Episteme-ology of Science Fiction. Morse, Donald (ed), In Anatomy of Science Fiction (pp. 10-25). Newcastle: Cambridge Scholar Press.

Freese, P. (2009). The clown of Armageddon : the novels of Kurt Vonnegut. Heidelberg: Winter.

Hume, K. (1998). Vonnegut's Melancholy. Philological Quarterly77, , (2), 221-238.

Klinkowitz, J. (1982). Kurt Vonnegut. New York: Methuen.

Lundquist, J. (1980). Kurt Vonnegut. New York: Frederick Ungar.

Mann, G. (2001). The Mammoth Encyclopedia of Science Fiction. London: Robinson.

Morse, D. E. (2006). Anatomy of science fiction. Newcastle: Cambridge Scholars Press.

Nagano, Fumika. (2009). Surviving Perpetual Winter: The Role of Little Boy in Vonnegut's Cat's Cradle in Kurt Vonnegut (pp. 127-140). New York: Infobase Publishing

Vonnegut, K. (1965). God Bless you, Mr. Rosewater. New York: Delacorte.

Vonnegut, K. (1976). Slapstick: or, Lonesome no more! : a novel. New York: Delacorte Press.

Vonnegut, K. (1985). Galápagos. New York: Dial Press.

Vonnegut, K. (2006). Wampeters, Foma, and Granfaloons. New York: Delacorte.

Vonnegut, K. (2007). Slaughterhouse-Five. Dial Press.

Vonnegut, K. (2011). Cat's Cradle. London: Penguin.

Arab World English Journal for Translation \& Literary Studies 